\title{
Bioassay for the Response of Resveratrol Transgenic Rice Lines to Bacterial and Fungal Diseases
}

\author{
Yang Qin ${ }^{1}$, Suk-Man Kim ${ }^{2}$, Hong-Il Ahn ${ }^{1}$, Jin-Hyoung Lee ${ }^{1}$, So-Hyeon Baek ${ }^{3}$, Kong-Sik Shin ${ }^{1}$, Hee-Jong Woo ${ }^{1}$, \\ Hyun-Suk Cho', Soon-Jong Kweon', Myung-Ho Lim* \\ ${ }^{1}$ Biosafety Division, National Academy of Agricultural Science, RDA, Suwon 441-707, Korea \\ ${ }^{2}$ Plant Breeding, Genetics and Biotechnology Division, International Rice Research Institute (IRRI), c/o IRRI-Korea Office, National \\ Institute of Crop Science, RDA, Suwon 441-857, Korea \\ ${ }^{3}$ Rice Breeding and Cultivation Research Division, National Institute of Crop Science, RDA, Iksan 570-080, Korea
}

\begin{abstract}
Resveratrol is a stilbenoid and phytoalexin produced in response to stresses, such as wounding, and pathogen attacks by bacteria or fungi. Two resveratrol rice lines, Iksan 515 and Iksan526, were used to examine resistance against Korean pathogen races for bacterial blight, leaf blast, and brown leaf spot. The screening test for bacterial blight demonstrated an increased susceptibility of both transgenic lines to K1 race, and a more susceptible Iksan515 to K2. Phenotypic evaluation for resistance to brown leaf spot also revealed the susceptibility of Iksan526 to the disease which did not significantly differ from the isogenic variety 'Dongjin', and a slightly more susceptible Iksan515 to the disease compared to check. When the lines were screened with three races (KJ301, KJ101 and KJ133) of leaf blasts in the field, both transgenic lines exhibited resistance but at the same level with 'Dongjin'. Our overall findings suggest that foreign phytoalexin resveratrol production in transgenic rice lines transformed with resveratrol synthase gene did not confer resistance against fungal and bacterial diseases.
\end{abstract}

Keywords Transgenic rice, Resveratrol, Bacterial blight, Brown leaf spot, Leaf blast

\section{INTRODUCTION}

Resveratrol is a phytoalexin that has antifungal activity and is produced in response to stress, such as pathogens and wounds (Langcake \& Pryce 1976). Resveratrols are synthesized via the phenylpropanoid pathway from three molecules of malonyl-CoA and one molecule of coumaroyl-CoA, and this process is catalyzed by stilbene synthase (Rupprich et al. 1980). Many stilbene synthase (STS) genes, including $V s t 1, V s t 2, V s t 3$, and StSy from grapevine (Wiese et al. 1994); PST-1, PST-2, PST-3, PST-4, and PST-5 from pine (Preisig-Müller et al. 1999); AhRS gene from Arachis hypogea (Hain et al. 1990); and SbSTS1 gene from Sorghum bicolor (Yu et al. 2005), have been characterized and transformed into plants to increase resistance against fungal and bacterial diseases.

Some STS genes are highly expressed with considerable amounts of cis- or trans-resveratrol production and their expression is related with resistance against fungi or bacteria in genetically modified (GM) crops. Hain et al. (1993) developed transgenic tobacco with Vst1 and Vst2; Stark-Lorenzen et al. (1998) and Tian et al. (1998) both developed transgenic rice with Vst1; and Liang et al. (2000) and Serazetdinova et al. (2005) developed transgenic wheat with $V s t 1 / V s t 2$ and $P S S$ gene, respectively. However, some STS GM plants produced piceid or failed to produce resveratrol. For instance, the transgenic kiwifruit produced by Kobayashi et al. (2000), transgenic white poplar generated by Giorcelli et al. (2004) and transgenic strawberry produced by Hanhineva et al. (2009) were more susceptible to fungi.

Four hypotheses have been proposed to explain stilbene GM plants that lack resistance or are more susceptible to fungal pathogens. First, a constitutive CaMV35S promoter triggered strong and constitutive stilbene accumulation but

Received August 5, 2013; Revised September 3, 2013; Accepted September 4, 2013; Published September 30, 2013

*Corresponding author Myung-Ho Lim, mlim312@korea.kr, Tel: +82-31-299-1126, Fax: +82-31-299-1122 
caused a drastic depletion of the endogenous precursor pools. This affects stilbene production and may interfere with secondary biosynthetic pathways (Hain et al. 1990, 1993; Thomzik et al. 1997). Second, these GM plants may produce resveratrol glucoside (piceid), which has little or no antifungal activities compared with resveratrol and its dehydrodimer $\delta$-viniferin, which are more effective against fungus ( $P$. viticola) zoospores in grapevines (Kobayashi et al. 2000; Giorcelli et al. 2004; Chang et al. 2011). Third, host-pathogen relationships determine the antifungal activity of foreign resveratrol production (Thomzik et al. 1997). Finally, the introduction of stilbene genes into plants causes major changes in the biosynthesis of phenolic compounds. Altered metabolite profiles, especially endogenous chalcone synthase downregulation, can increase the susceptibility of GM plants against fungal pathogens (Hanhineva et al. 2009).

Previous studies have demonstrated that the quantity of resveratrol production from GM plants with inserted stilbene synthase genes was often much lower than the amounts of piceid and other phenolic compounds that were produced. Moreover, stilbene concentrations and antimicrobial activity were unpredictable. Two studies have been published on transgenic rice with the stilbene synthase gene Vst1 under the control of a pathogen-inducible promoter (Stark-Lorenzen et al. 1998; Tian et al. 1998). Both GM rices were resistant to leaf blast, but the rice line described by Tian et al. (1998) also showed resistance to bacterial blight. However, resveratrol production and concentration were not characterized in either study. Here, we investigated the responses against bacterial blight, leaf blast, and brown leaf spot in two independent transgenic lines Iksan515 and Iksan526 (RS18, Baek et al. 2013) that were developed by introducing the AhSTS1 gene (RS3, GenBank accession no. DQ124938) under the control of the ubiquitin promoter into the 'Dongjin' commercial rice variety (Baek et al. 2013).

\section{MATERIALS AND METHODS}

\section{Plant materials and molecular information}

Two resveratrol transgenic rice lines Iksan515 and Iksan526 were screened for resistance to bacterial blight, leaf blast, and brown leaf spot. Both lines were generated by the introduction of the resveratrol synthase gene (AhSTS1, $R S 3)$ under the control of the maize Ubi 1 promoter and the bialaphos resistance (bar) gene under the control of the CaMV35S promoter (Fig. 1A, B). These were inserted into the intergenic regions of chromosome 4 and 12, respectively, with both inverted repeats of two T-DNA insertions.

\section{Transgene expression}

Reverse transcription polymerase chain reaction (RT-PCR) and immune-strip tests were performed to confirm resveratrol synthase and bar gene expression. Total RNA was isolated from rice leaves with TRIzol according to the manufacturer's instructions (Invitrogen). cDNA was synthesized by using the SuperScript III First-Strand Synthesis System (Invitrogen). The PCR condition were as follows: a predenaturation step at $94^{\circ} \mathrm{C}$ for $3 \mathrm{~min} ; 28$ cycles of denaturation at $94^{\circ} \mathrm{C}$ for $30 \mathrm{~s}$, annealing at $57^{\circ} \mathrm{C}$ for $30 \mathrm{~s}$, extension for $1 \mathrm{~min}$ at $72^{\circ} \mathrm{C}$; and final extension for $5 \mathrm{~min}$ at $72^{\circ} \mathrm{C}$. The primer pair for RS was fw-ATGGTGTCTGTGAGTGGAATTCGC and rv-TTATATGGCCACACTGCG and for actin was fw-CTGCTATGTACGTCGCCATC and rv-GTCTCATG GATACCCGCAG.

\section{Bacterial culture and inoculation}

Four Korean races (K1, K2, K3, and K3a) of the bacterial blight pathogen Xanthomonas oryzae pv. oryzae (Xoo) were cultured on media containing $5 \mathrm{~g}$ yeast extract, $10 \mathrm{~g}$ tryptone, $5 \mathrm{~g}$ sodium chloride, $5 \mathrm{~g}$ sucrose, and $0.5 \mathrm{~g}$ $\mathrm{MgSO}_{4}$ per liter and were allowed to grow at $28^{\circ} \mathrm{C}$ for 3 to $4 \mathrm{~d}$. The bacterial cells were suspended in sterile distilled water and adjusted to $10^{8} \mathrm{cfu} / \mathrm{ml}$ using a spectrophotometer at an $\mathrm{OD}_{600}$ value of 0.5 .

The bacterial cell suspension was applied to the flag and the top second leaves of each tiller of both transgenic lines and the donor variety at maximum tilling stage in the greenhouse by clipping $2-3 \mathrm{~cm}$ from the tip of the leaf using a pair of scissors dipped in the inoculum. Lesion length was measured two weeks after inoculation. Twenty leaves and three replications for each line were used for disease evaluation. Percent disease incidence was calculated according to formula as follows: $\%$ Disease severity $=$ Total lesion length/Total leaf length $\times 100$. 
A

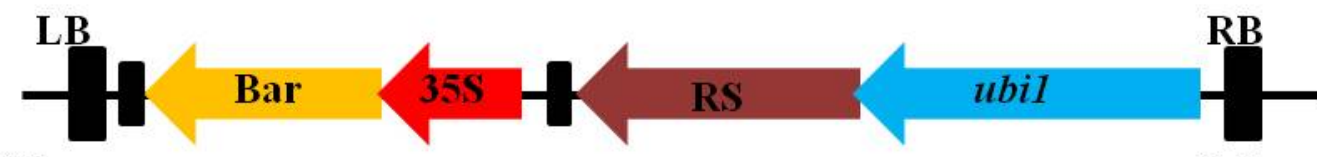

B

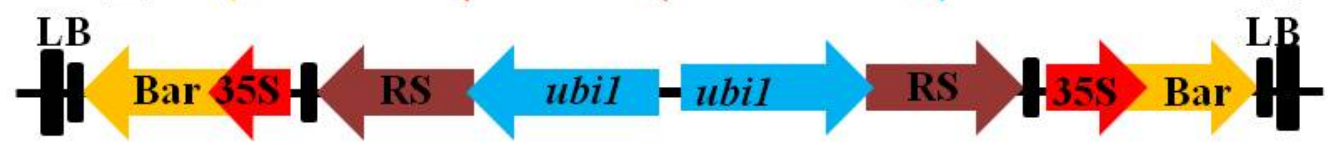

C

DJ I515 I526

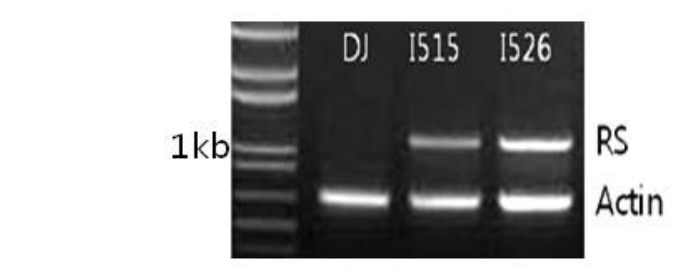

D

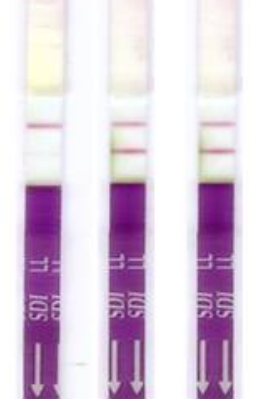

Fig. 1. Molecular information for two transgenic rice lines.

A. Transformation vector constructs of two transgenic rice lines. $R S$, resveratrol synthase gene; $35 \mathrm{~S}, \mathrm{CaMV} 35 \mathrm{~S}$ promoter; ubi1, maize ubiquitin promoter; B. inserted T-DNA structure for two transgenic lines; C. gene expression of inserted resveratrol synthase in rice leaves, as analyzed by RT-PCR; OsActin was used as a loading control; D. PAT protein (bar) expression tested by immuno strips from young leaves. Two red bands were found for both transgenic lines, indicating successful transformations and bar gene expression, compared to single band for the isogenic variety 'Dongjin'.

\section{Evaluation for brown leaf spot resistance}

Approximately 30-day-old seedlings of Iksan515, Iksan526 and 'Dongin' were transplanted in rows at $15 \times 30 \mathrm{~cm}$ apart in a genetically modified organism (GMO) isolation field at Gunwi, Gyeongbuk province, Korea on June 2, 2011. Field management was done following the standard methods for rice cultivation of Rural Development Administration (RDA, Korea). Thereafter, the plants were observed for the natural infection with brown leaf spot. Disease severity was determined by taking the average number of lesions per leaf area $\left(\mathrm{cm}^{2}\right)$ of 20 flag leaves, 20 second leaves, and 20 third leaves for each rice line at maturity stage.

\section{Evaluation for leaf blast resistance}

Lines of Iksan515, Iksan526 and Dongjin were planted in a row spaced at $10 \mathrm{~cm}$ apart. Three rows planted with 'Nagdong' were established beside the test lines as spreader or source of inoculum for natural infection (Fig. 3B). The experiment was setup at Suwon GMO experimental field in July 2012. Overhead irrigation was performed 2-3 times a

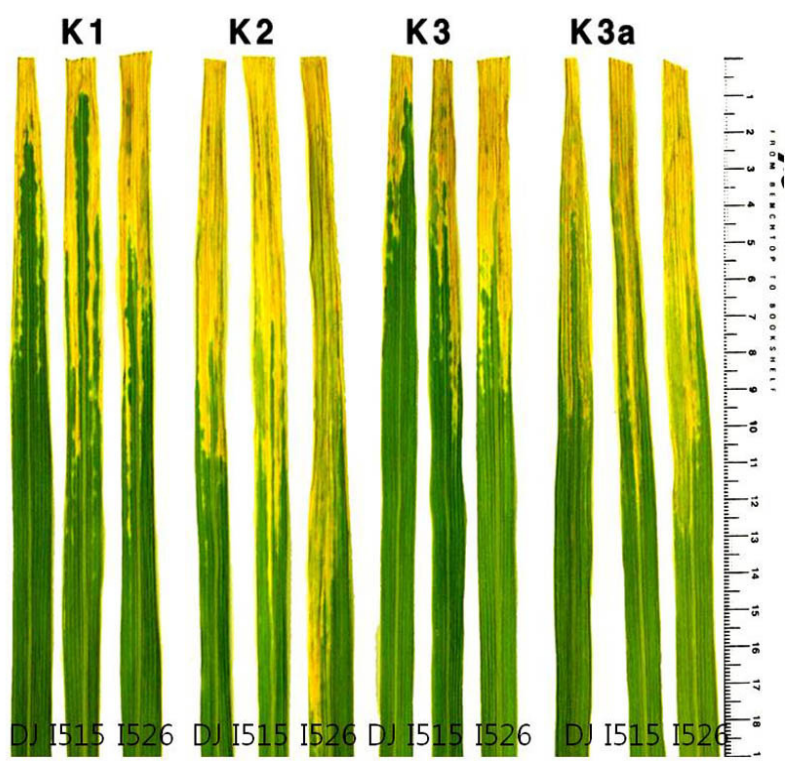

Fig. 2. The representative leaf performance of the two resveratrol rice lines Iksan515 and Iksan526 and their isogenic variety 'Dongjin' in response to four Korean races (K1, K2, K3, and K3a) of bacterial blight at $14 \mathrm{~d}$ after inoculation. DJ, 'Dongjin'; I515, Iksan515; I526, Iksan526. 
day throughout the growing period after sowing. Disease infection was monitored for 40-d-old seedlings. Lesions were scored on a scale of 1 (resistant, small, brown, pinpoint-sized specks) to 9 (susceptible, typical leaf blast lesions, $3 \mathrm{~mm}$ or longer, infecting more than $75 \%$ of the leaf area) in accordance with the Standard Evaluation System (SES, IRRI 2002).

\section{RESULTS}

\section{Transgene expression analysis}

The $T_{6}$ generation lines of resveratrol transgenic rice (Iksan515 and Iksan526) were used for transgene expression profiling. Resveratrol synthase gene expression in the young rice leaves was confirmed by RT-PCR for both transgenic lines while it was absent in the isogenic variety 'Dongjin' (Fig. 1C). The selectable marker bar gene was stably expressed in the fresh young leaves of both transgenic lines (Fig. 1D) as assessed by immuno-strip assay (PAT). In a related study, approximately $48 \mu \mathrm{g} / \mathrm{g}$ piceid and less than $1 \mu \mathrm{g} / \mathrm{g}$ resveratrol were detected in the leaves of Iksan515 and Iksan526 (RS18) by high-performance liquid chromatography (HPLC) (Baek et al. 2013). The different insertion sites of the two transgenic lines indicate that they are independent lines. T-DNAs of both lines were inserted into intergenic regions of rice chromosomes, suggesting that unintended consequences, such as gene disruption at the insertion site, did not occur.

\section{Transgenic rice lines response to bacterial blight}

Both transgenic rice lines and 'Dongjin' were susceptible (lesion length $>5 \mathrm{~cm}$ ) to all four bacterial blight races based on SES disease index. Significant differences between 'Dongjin' and Iksan515 were observed for K1 $\left(\mathrm{t}=5.13^{* *}\right)$ at 0.01 and $\mathrm{K} 2\left(\mathrm{t}=4.22^{* *}\right)$ at 0.05 significance levels, and a significant difference between 'Dongjin' and Iksan526 was noted on response to $\mathrm{K} 1$ race $\left(\mathrm{t}=2.56^{*}\right)$ at 0.01 significance level. This indicates that Iksan515 is more susceptible than Iksan526 to K1 and K2 races. Differences

Table 1. Disease severity of transgenic lines and their isogenic variety response to four bacterial blight races (K1, K2, K3, and $\mathrm{K} 3 \mathrm{a}$ ) of Korea evaluated after 14 days of inoculation in a GMO greenhouse.

\begin{tabular}{ccccccc}
\hline \hline \multirow{2}{*}{ Races/lines } & \multicolumn{5}{c}{ Disease severity $(\%$, lesion length / total leaf length) } \\
\cline { 2 - 6 } & Dongjin & & Iksan515 & $\mathrm{t}$ & Iksan526 & $\mathrm{t}$ \\
\hline K1 & $7.47 \pm 1.51^{\mathrm{a}}$ & - & $13.37 \pm 4.37$ & $5.13^{* \mathrm{c}}$ & $14.15 \pm 2.53$ & $4.22 * *$ \\
K2 & $11.16 \pm 1.79$ & - & $18.83 \pm 5.14$ & $2.56^{* \mathrm{~b}}$ & $12.14 \pm 1.87$ & 0.53 \\
K3 & $7.00 \pm 1.85$ & - & $9.33 \pm 4.19$ & 0.64 & $8.24 \pm 2.05$ & 0.77 \\
K3a & $8.79 \pm 1.19$ & - & $11.55 \pm 1.93$ & 1.70 & $12.44 \pm 2.50$ & 1.86 \\
\hline
\end{tabular}

\footnotetext{
${ }^{\mathrm{a}}$ Mean \pm standard deviation

${ }^{\mathrm{b}}$ t-test implied significant difference between transgenic lines and Dongjin at the 0.05 level

${ }^{c}$ t-test implied significant difference between transgenic lines and Dongjin at the 0.01 level
}

Table 2. Disease incidence on the flag, second, and third leaves of transgenic lines and their isogenic variety response to leaf brown spot after natural infection in the Gunwi GMO experimental field.

\begin{tabular}{|c|c|c|c|c|c|c|}
\hline \multirow{2}{*}{ Leaf position/lines } & \multicolumn{6}{|c|}{ Number of lesions / leaf area $\left(\mathrm{cm}^{2}\right)$} \\
\hline & Dongjin & & Iksan515 & $\mathrm{t}$ & Iksan526 & $\mathrm{t}$ \\
\hline Flag leaf & $0.21 \pm 0.10^{\mathrm{a}}$ & - & $0.63 \pm 0.25$ & $2.27 * * \mathrm{~b}$ & $0.38 \pm 0.13$ & 1.47 \\
\hline The second leaf & $0.20 \pm 0.12$ & - & $0.36 \pm 0.25$ & 0.87 & $0.20 \pm 0.14$ & 0.00 \\
\hline The third leaf & $0.34 \pm 0.08$ & - & $0.64 \pm 0.40$ & 1.05 & $0.35 \pm 0.20$ & 0.07 \\
\hline Means of upper three leaves & $0.25 \pm 0.12$ & - & $0.54 \pm 0.33$ & $7.12 * *$ & $0.31 \pm 0.18$ & 2.03 \\
\hline
\end{tabular}


in the severity of leaf blight caused by K3 and K3a races were not statistically significant between 'Dongjin' and the two transgenic lines, although the later tend to be more susceptible over time compared to 'Dongjin'. However, it should be noted that high standard deviations ( \pm 4.37 for $\mathrm{K} 1, \pm 5.14$ for K2) and relatively large ranges between the investigated individuals $(9.0-17.74$ for $\mathrm{K} 1,13.69-23.97$ for K2) of the bacterial blight severity for Iksan515 was the likely reason for significant differences $\left(\mathrm{t}=5.13^{* *}\right.$ for $\mathrm{K} 1$, $\mathrm{t}=2.56^{*}$ for K2) compared to the response of 'Dongjin'.

\section{Transgenic rice lines response to brown leaf spot}

The flag leaf of 'Dongjin' and Iksan515 exhibited reactions to brown leaf spot which were significantly different to each other $\left(\mathrm{t}=2.27^{* *}\right)$ at 0.01 significance level. In addition, Iksan515 showed more infected lesions on the second and third leaves compared to Iksan526. However, Iksan526 responses to brown leaf spot were not significantly different to Dongjin on the flag leaf, second leaf, and third leaf (Table 2). More lesions were observed on the flag leaves of Iksan515 (Fig. 3A) compared to Iksan526 and 'Dongjin' which both displayed the same number. Overall, the brown leaf spot response of Iksan515 was significantly different $\left(\mathrm{t}=7.12^{* *}\right)$ from 'Dongjin', but not to Iksan526. The severity (number of lesions/leaf area $\left(\mathrm{cm}^{2}\right)$ ) of Iksan515 was the most highly variable among the treatment genotypes with values ranging from $0.38-0.88$ on flag leaf, $0.11-0.61$ on the second leaf, and $0.24-1.04$ on the third leaf,

A

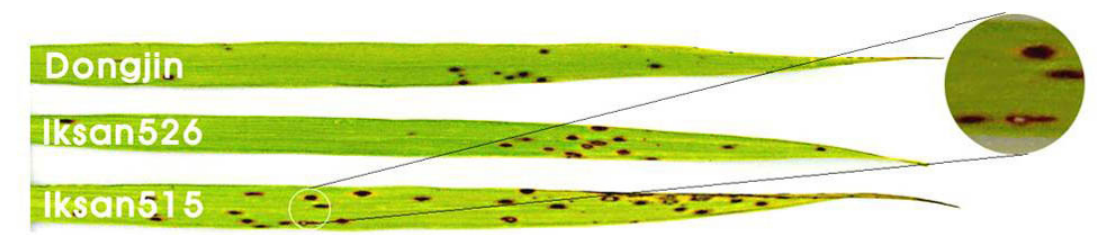

B
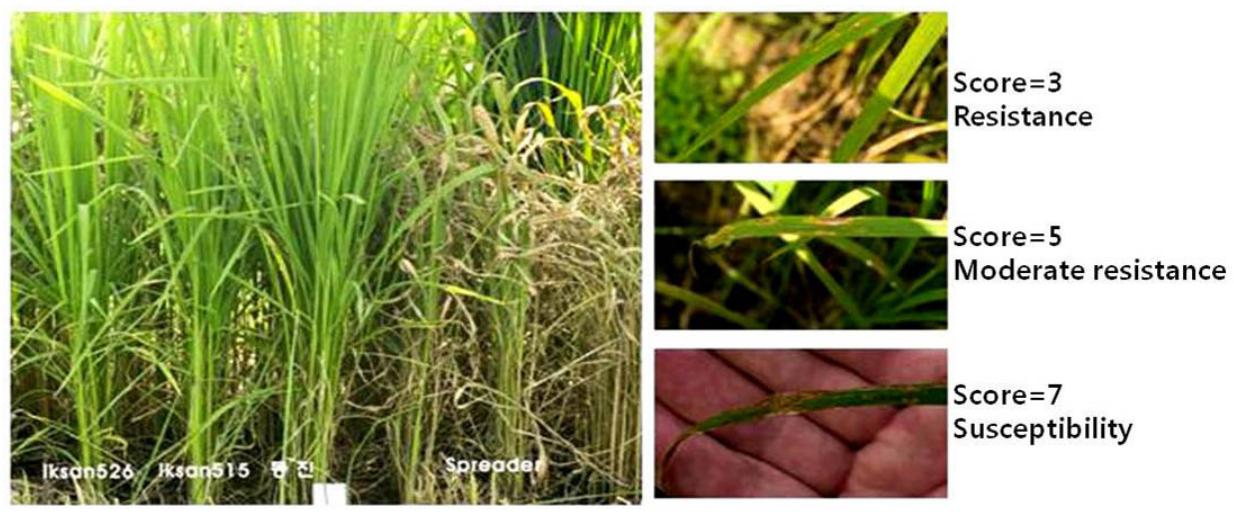

Score $=7$

Susceptibility

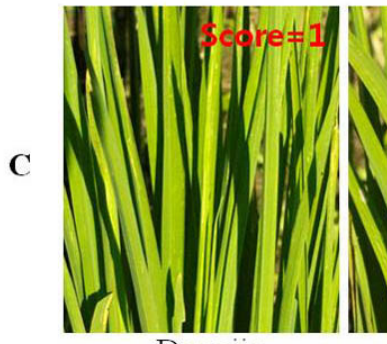

Dongjin

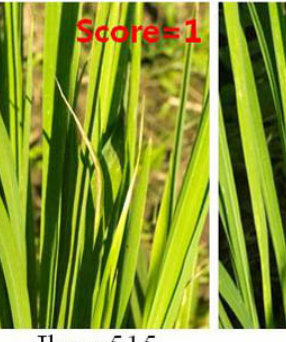

Iksan 515

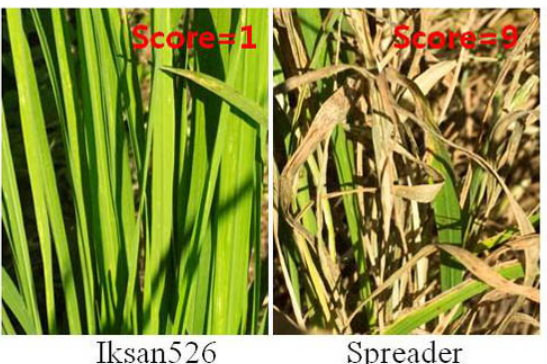

Spreader

Fig. 3. Evaluation for brown leaf spot and leaf blast by natural infection in the Gunwi and Suwon GMO experimental fields, respectively. A. flag leaves of the transgenic rice lines and their isogenic variety 'Dongjin' in response to brown leaf spot in the Gunwi GMO experimental field; B. layout of 'Dongjin', Iksan515, Iksan526, and spreader rows of leaf blast (seedlings) by natural infection at the Suwon GMO experimental field and the evaluation criteria for resistance, moderate resistance, and susceptibility; C. evaluation for leaf blast in the case of the transgenic rice lines Iksan515 and Iksan526 and their isogenic variety 'Dongjin'. 
compared to 'Dongjin' which had corresponding value of $0.11-0.31,0.08-0.32$ and $0.26-0.42$, and to Iksan 526 which also revealed $0.25-0.51,0.06-0.34$ and $0.15-0.55$ severity score, respectively. This may have probably caused the significant difference $\left(\mathrm{t}-7.12^{* *}\right)$ observed at 0.01 significance level between Iksan515 and 'Dongjin'.

\section{Transgenic rice lines response to leaf blast disease}

The transgenic lines and 'Dongjin' showed resistance $($ Scale $=1)$ to leaf blast which was highly incomparable to the susceptible cultivar 'Nagdong' (Scale =9, Fig. 3C). Although we did not observe significant differences in the response between transgenic lines and the isogenic variety to blast races influencing Suwon rice production such as KJ301, KJ101, and KJ133. Likewise, in the present study Dongjin showed higher resistance (scale $=1$ ) to leaf blast compared when the screening was done in Suwon region where it got only moderate resistance (scale $=5$ ). This is possibly due to the environmental conditions of the GMO experimental field in Gunwi such as low humidity and temperature.

\section{DISCUSSION}

We found out that production of the secondary metabolite phytoalexin resveratrol induced by resveratrol synthase gene insertion into the transgenic rice lines Iksan515 and Iksan526 did not inprove the resistance to bacterial blight and brown leaf spot. Both transgenic lines exhibited showed resistance to rice blast but at level comparable to the isogenic variety 'Dongjin'. Most studies on transgenic crops overexpressing stilbene synthase reported increased resistance against bacterial and fungal diseases (Hain et al. 1993; Stark-Lorenzen et al. 1997; Tian et al. 1998; Hipskind et al. 2000; Liang et al. 2000; Coutos-Thevenot et al. 2001; Zhu et al. 2004; Lim et al. 2005; Serazetdinova et al. 2005; Liu et al. 2011). However, no resistance or increased susceptibility conferred by stilbene synthase gene transformation has been reported in transgenic tomato, kiwifruits, white poplar, or strawberry (Thomzik et al. 1997; Kobayashi et al. 2000; Giorcelli et al. 2004; Hanhineva et al. 2009). Here, we present the contradictory conclusions from previous studies about piceid production and concentrations, hostpathogen relationships, desirable promoters, and alternations of biosynthesis pathways.

First, a number of transformation experiments designed to produce resveratrol-3-glucoside (piceid), resveratrol derivatives, or no resveratrol in GM kiwifruit and strawberry transformed with the stilbene synthase gene resulted to an increased susceptibility or no resistance against Botrytis cinerea (Kobayashi et al. 2000; Hanhineva et al. 2009). At that time no studies have been conducted yet comparing the antifungal activity of piceid and resveratrol. Schouten et al. (2002) studied the laccase Bclcc 2 gene from Botrytis cinerea and found that it converts resveratrol into more toxic compounds and induces self-intoxication to protect the grapevine (Vitis) from Botrytis cinerea infection. This contradicts the previous theory that resveratrol detoxifies. However, $B c l c c 2$ laccase was only expressed in the presence of resveratrol or tannins, not piceid. Resveratrol exerts antifungal activity against grapevine pathogens, but resveratrol seems to be more than a final product (Chang et al. 2011). Resveratrol can be further metabolized into oxidative $\delta$ -viniferin that is even more effective against $P$. viticola zoospores or into the ineffective glycoside piceid, which does not show any toxic activity against $P$. viticola zoospores even at concentration more than $100 \mu \mathrm{M}(390 \mu \mathrm{g} / \mathrm{ml})$, at least 5 times that of resveratrol and 10 times that of $\delta$ -viniferin. White poplar was transformed with a stilbene synthase (StSy) gene from grapevine by Giorcelli et al. (2004), and a total of $615.2 \mu \mathrm{g} / \mathrm{g}$ trans- and cis-isomers piceid was detected in the fresh weight (FW) transformants, but no resistance against the pathogen Melampsora pulcherrima was observed.

However, piceid was also identified at a concentration of $0.5-20 \mu \mathrm{g} / \mathrm{g} \mathrm{FW}$ in the leaves of transgenic alfalfa transformed with $R S$ under the control of CaMV35S promoter by Hipskind et al. (2000) and transgenic papaya with Vst1 insertion under the control of the pathogen-inducible promoter $V s t 1$ at a concentration of $54 \mu \mathrm{g} / \mathrm{g}$ by Zhu et al. (2004). Both plants showed resistance to the fungal pathogens Phoma medicaginis and Phytophthora palmivora. Moreover, Liu et al. (2011) overexpressed a resveratrol synthase gene (PcRS) in transgenic Arabidopsis, which led to the accumulation of 93.31 to $183.73 \mu \mathrm{g} / \mathrm{g}$ (FW) trans-piceid 
and resulted in enhanced resistance against the fungal pathogen $C$. higginsianum. These studies indicate that low concentrations of piceid can confer resistance against fungal pathogens to some extent. It is unclear whether these findings suggests that foreign piceid has antifungal activity or if a different mechanism is at work in grapevine due to the existence of endogenous piceid.

Second, antifungal activity of foreign resveratrol may depend on the relationships between hosts and pathogens. Thomzik et al. (1997) transferred two genes from the grapevine coding for stilbene synthase into tomato. The accumulation of phytoalexin trans-resveratrol was detectable after fungal inoculation and resulted in a significant increase in the resistance of transgenic tomato to Phytophthora infestans but no significant increase in resistance to Botrytis cinerea and Alternaria solani. Therefore, they assumed that the foreign phytoalexin resveratrol only affected hostpathogen relationships, such as those involving the biotrophic or hemibiotrophic pathogen P. infestans and necrotrophic pathogens such as Alternaria and Botrytis, all of which were less sensitive to the presence of resveratrol. However, transgenic tobacco, rice, alfalfa, wheat, Arabidopsis, and Rehmannia glutinosa showed resistance to necrotrophic pathogens, but transgenic poplar showed no resistance to the biotrophic pathogen Melampsora pulcherrima, suggesting no direct relationship between foreign phytoalexin resveratrol and the pathogen type.

Third, pathogen-inducible promoters used to control stilbene synthase genes are favorable to confer GM plants with pathogen resistance. Three types of promoters consisting of constitutive promoter CaMV35S (transgenic alfalfa, kiwifruit, poplar, rehmannia glutinosa, strawberry, and Arabidopsis), pathogen-inducible promoters Vst1 (transgenic tobacco, tomato, rice, wheat, and papaya) and PR10 (grapevine), and floral filament-specific promoter fill (strawberry) have been used to control stilbene gene expression in previous studies. The CaMV35S promoter often triggered strong and constitutive stilbene accumulation followed by a drastic depletion of the endogenous precursor pools. In contrast, the pathogen-inducible promoter appears to be a promising way to maintain precursor pool levels as suggested by Delaunois et al. (2009), allowing strong stilbene accumulation at the infection site. At least three studies were done involving transformation of the stilbene genes under the control of the CaMV35S promoter which enhanced resistance to fungal pathogens (Hipskind et al. 2000; Lim et al. 2005; Liu et al. 2011). But, no resistance to Botrytis cinerea and Alternaria solani was reported for transgenic tomato under the control of pathogen-inducible promoter Vst1 (Thomzik et al. 1997). Therefore, different promoters may not provide a reasonable explanation on susceptible responses against pathogens by foreign stilbene resveratrol or piceid transformation.

Finally, alternations of phenolic compounds up- and downstream of resveratrol synthase upset the balance of the phenylpropanoid pathway. Increased phenolic compounds and decreased flavonol and chalcone synthase transcript levels led to increased susceptibility to grey mold fungus in transgenic strawberry (Hanhineva et al. 2009). Furthermore, altered seed coat pigmentation and significant reductions in anthocyanin levels were observed in transgenic Arabidopsis, but chalcone synthase was not downregulated (Liu et al. 2011). These two studies proposed that additional stilbene synthase activities limited the supply of precursors for chalcone synthase, which caused unbalanced flavonoid biosynthesis. Piceid production, low stilbene concentrations, constitutive promoter activity, and stilbene biosynthesis pathway alterations are possible reasons for the lack of antifungal activity in connection with foreign stilbene gene expression. Likewise, phytoalexin stilbene transformations seem to result in unpredictable stilbene production, expression levels, and antifungal activities.

In the present study, resveratrol synthase gene (RS3) was transformed into rice under the control of maize ubil promoter, and expression was confirmed in both transgenic lines. HPLC confirmed that Iksan 526 contained approximately $48 \mu \mathrm{g} / \mathrm{g}$ trans-piceid and less than $1 \mu \mathrm{g} / \mathrm{g}$ resveratrol in leaves (Baek et al. 2013). Similar concentrations of resveratrol and trans-piceid were also reported for Iksan515. Except for leaf blast, Iksan 515 showed much susceptible responses to $\mathrm{K} 1$ and $\mathrm{K} 2$ races of bacterial blight and brown leaf spot compared to the isogenic variety 'Dongjin'. A highly variable severity of both diseases in Iksan515 lines suggests that individual segregation or phenotypic mutations occurred during the rice tissue culture. Taken together, resveratrol rice lines transformed with resveratrol synthase gene did 
not show increased resistance to the three pathogens investigated in this study. Based on the data discussed above, the use of the constitutive promoter ubi1, relatively low production of resveratrol and piceid $(48 \pm 1 \mu \mathrm{g} / \mathrm{g})$, and the alterations of phenolic acids or competition for the precursors of resveratrol synthase and chalcone synthase probably resulted in increased susceptibility to bacterial and fungal diseases for both transgenic lines Iksan515 and Iksan526. In addition, foreign gene introduction and chromosome rearrangement during tissue culture may have upset the chromosome balance and contributed to unpredictable foreign stilbene transformation. To further define the up- and downregulation of enzymes that is crucial to resveratrol production in the phenylpropanoid pathway, such as phenylalanine ammonia-lyase (PAL), cinnamate 4-hydroxylase ( $\mathrm{C} 4 \mathrm{H})$, 4-coumarate CoA ligase $(4 C L)$, and chalcone synthase (CHS), as well as resveratrol synthase (RS), future studies should employ real-time PCR to assess both transgenic lines at different time points after pathogen inoculation.

\section{ACKNOWLEDGMENT}

This work was equally supported by grant PJ009528 from the Biogreen 21 R\&D Program and grant PJ009652 from the National Academy of Agricultural Science, Rural Development Administration, Republic of Korea.

\section{REFERENCES}

Baek SH, Shin WC, Ryu HS, Lee DW, Moon EJ, Seo CS, Hwang E, Lee HS, Ahn MH, Jeon YJ, Kang HJ, Lee SW, Kim SY, Dsouza R, Kim HJ, Hong ST, Jeon JS. 2013. Creation of resveratrol-enriched rice for the treatment of metabolic syndrome and related diseases. PLoS One 8: e57930.

Chang XL, Heene E, Qiao F, Nick P. 2011. The phytoalexin resveratrol regulates the initiation of hypersensitive cell death in Vitis cell. PLoS One 6: e26405.

Coutos-Thévenot P, Poinssot B, Bonomelli A, Yean H, Breda C, Buffard D, Esnault R, Hain R, Boulay M. 2001. In vitro tolerance to Botrytis cinerea of grapevine 41B rootstock in transgenic plants expressing the stilbene synthase Vst 1 gene under the control of a pathogeninducible PR 10 promoter. J. Exp. Bot. 52: 901-910.

Delaunois B, Cordelier S, Conreux A, Clement C, Jeandet P. 2009. Molecular engineering of resveratrol in plants. Plant Biotechnology Journal 7: 2-12.

Giorcelli A, Sparvoli F, Mattivi F, Tava A, Balestrazzi A, Vrhovsek U, Calligari P, Bollini R, Confalonieri M. 2004. Expression of the stilbene synthase $(S t S y)$ gene from grapevine in transgenic white poplar results in high accumulation of the antioxidant resveratrol glucosides. Transgenic Res. 13: 203-214.

Hain R, Bieseler B, Kindl H, Schröder G, Stöcker R. 1990. Expression of a stilbene synthase gene in Nicotiana tabacum results in synthesis of the phytoalexin resveratrol. Plant Mol. Biol. 15: 325-335.

Hain R, Reif HJ, Krause E, Langebartels R, Kindl H, Vornam B, Wiese W, Schmelzer E, Schreier P, Stöcker R, Stenzel K. 1993. Disease resistance results from foreign phytoalexin expression in a novel plant. Nature 361: 153-156.

Hanhineva K, Kokko H, Siljanen H, Rogachev L, Aharoni A, Karenlampi SO. 2009. Stilbene synthase gene transfer caused alterations in the phenylpropanoid metabolism of transgenic strawberry (Fragaria $\times$ ananassa). J. Exp. Bot. 60(7): 2093-2106.

International Rice Research Institute. 2002. Standard Evaluation System for Rice. IRRI, Los Banos, Laguna, Philippines. p.56.

Kobayashi S, Ding CK, Nakamura Y, Nakajima I, Matsumoto R. 2000. Kiwifruits (Actinidia deliciosa) transformed with a Vitis stilbene synthase gene produce piceid (resveratrolglucoside). Plant Cell Rep. 19: 904-910.

Langcake P, Pryce CA. 1976. The production of resveratrol by Vitis vinifera and other members of Vitaceae as a response to infection or injury. Physiol. Plant Pathol. 9: 77-85.

Leckband G, Lörz H. 1998. Transformation and expression of a stilbene synthase gene of Vitis vinifera $L$. in barley and wheat for increased fungal resistance. Theor. Appl. Genet. 96: 1004-1012.

Liang H, Zhang J, Duan XY, Sheng BQ, Jia S, Wang DW, Ouyang JW, Li JY, Li LC, Tian WZ, Hain R, Jia X. 2000. A transgenic wheat with a stilbene synthase gene resistant to powdery mildew obtained by biolistic method. Chinese Science Bulletin 45(7): 634-638.

Lim JD, Yun SJ, Chung IM, Yu CY. 2005. Resveratrol synthase transgene expression and accumulation of resveratrol 
glycoside in Rehmannia glutinosa. Mol. Breed. 16: 219-233.

Liu ZY, Zhuang CX, Sheng SJ, Shao L, Zhao W, Zhao SJ. 2011. Overexpression of a resveratrol synthase gene (PcRS) from Polygonum cuspidatum in transgenic Arabidopsis causes the accumulation of trans-piceid with antifungal activity. Plant Cell Rep. 30: 2027-2036.

Preisig-Müller R, Schwekendiek A, Brehm I, Reif HJ, Kindl H. 1999. Characterization of a pine multigene family containing elicitor-responsivestilbene synthase genes. Plant Molecular Biology 39: 221-229.

Rupprich N, Hildebrand H, Kindl H. 1980. Substrate specificity in vivo and in vitro in the formation of stilbenes biosynthesis of rhaponticin. Arch Biochem Biophys. 200: 72-78.

Schouten A, Wagemankers L, Stefanato FL, Kaaij RM, Kan JAL. 2002. Resveratrol acts as a natural profungicide and induces self-intoxication by a specific laccase. Molecular Microbiology. 43(4): 883-894.

Serazetdinova L, Oldach KH, Lőrz H. 2005. Expression of transgenic stilbene synthases in wheat causes the accumulation of unknown stilbene derivatives with antifungal activity. J. Plant Physiol. 162: 985-1002.

Stark-Lorenzen P, Nelke B, Hänbler G, Mühlbach HP,
Thomzik JE. 1997. Transfer of a grapevine stilbene synthase gene to rice (Oryza sativa L.). Plant Cell Rep. 16: 668-673.

Thomzik JE, Stenzel K, Stöcker R, Schreier PH, Hain R, Stahl DJ. 1997. Synthesis of a grapevine phytoalexin in transgenic tomatoes (Lycopersicon esculentum Mill.) conditions resistance against Phytophthora infestans. Physiol. Mol. Plant Pathol. 51: 265-278.

Tian WZ, Ding L, Cao SY, Dai SH, Ye SQ, Li LC. 1998. Rice transformation with a phytoalexin gene and bioassay of the transgenic plants. Acta. Botanica. Sinica. 40(9): 803-808.

Wiese W, Vornam B, Krause E, Kindl H. 1994. Structural organization and differential expression of three stilbene synthase genes located on a $13 \mathrm{~kb}$ grapevine DNA fragment. Plant Mol. Biol. 26: 667-677.

Yu CKY, Springob K, Schmidt J, Nicholson RL, Chu IK, Yip WK, Lo C. 2005. A stilbene synthase gene (SbSTS1) is involved in host and non host defense responses in Sorghum. Plant Physiol. 138: 393-401.

Zhu YJ, Agbayani R, Jazckson MC, Tang CS, Moore PH. 2004. Expression of the grapevine stilbene synthase gene $V S T 1$, in papaya provides increased resistance against diseases caused by Phytophthora palmivora. Planta. 12: 807-812. 